\title{
A Market-Climate Change Model for Weather-Sensitive Sectors: Moving Average Approaches
}

\author{
Svetlana Vlady \\ Brooklyn College \\ The City University of New York
}

The weather has become more unpredictable and unseasonal. In Australia, weather-sensitive sectors are the key players in the economy. The main objective of this research is to raise awareness of environmental issues in investment decisions and develop a new Market-Climate Change Model. The Moving Average (MA), the Exponential Moving Average (EMA), and the Auto-Regressive Integrated Moving Average (ARIMA) techniques have been used to test a model. The results of this study indicate that weather-related variables influence the investment returns of weather-sensitive companies and should be included in the market model to support sound investment decisions.

\section{INTRODUCTION}

Very unusual swings in the weather and climate are seen throughout the world today, and the weather has become more unusual and unseasonal. During the $21^{\text {st }}$ century, the frequency of unseasonable weather has increased, while the severity of weather events has become greater every year. In 2016-2018, parts of the world experienced record-breaking low temperatures in the winter and even snow in the summer, while other parts suffered extreme summer heatwaves, resulting in significant damage and economic losses.

According to the United States National Weather Service (NWS, 2018), more than $50 \mathrm{~cm}$ of snow blanketed parts of the United States in January 2018. Freezing weather and powerful winter storms even brought snow to Florida. At the same time, temperatures reached near $-50{ }^{\circ} \mathrm{C}$ in eastern Canada, and a low temperature of $-88.6^{\circ} \mathrm{F}$ or $-67^{\circ} \mathrm{C}$ was recorded in the remote Russian region of Yakutia (Rice, 2018).

The year 2017 also saw catastrophic weather in the United States, including heavy flooding and rains accompanied by great amounts of hail, tornados, thunderstorms, strong winds, and rain. In the winter of 2017, massive snowfalls covered vast areas of Eastern and Central Europe amid tremendously cold temperatures (Climate Council, 2017). Unbelievably, heavy snows blanketed Santiago and Moscow during the summer and some parts of Eastern Europe during the spring (Hydrometeorological Centre of Russia, 2017; Vomiero, 2017).

In 2016, the North Pole faced melting temperatures, while abnormally cold conditions gripped Eurasia. For example, in November 2016, Siberia saw temperatures $60^{\circ}$ below normal, but temperatures soared above $32^{\circ} \mathrm{C}$, the highest recorded levels in the Arctic (Weather Channel, 2016). Astonishingly, in 2016, golf-ball-sized was reported in Kansas, tennis ball-sized hail in Texas, and volleyball-sized hail in Siberia (National Oceanic and Atmospheric Administration, 2016; Siberian Times, 2016). 
In 2016-2018, the eastern United States and Eurasia experienced record-breaking low winter temperatures, while Australia suffered extreme summer heatwaves resulting in catastrophic bushfires, power failures, and hospital admissions for heatstroke. In January 2018, drivers in Victoria encountered melting roads. Temperatures in the Sydney region reached a record-breaking $117^{\circ} \mathrm{F}$ or $48^{\circ} \mathrm{C}$, the hottest recorded since 1939 (Australian Bureau of Meteorology [ABM], 2018). According to the Australian Climate Council (ACC, 2017), "hot days have doubled," and heatwaves have become hotter, longer, and more frequent in Australia (p. 3).

People throughout the world face the reality of climate variability. According to Munich Re (2017), overall losses from world-wide natural catastrophes and weather extremes totaled US\$175 billion in 2016, up from US\$132 billion in 2015. Losses were US\$353 billion in 2017, higher than in 2016. Global losses are expected to be significantly higher in 2018 than 2017 and to continuously increase in the future. For example, according to the ACC (2017), bushfires alone cost the Australian economy AUD\$180 million annually. That amount is expected to more than double over the next 30 years, rising to AUD\$378 million by 2050 (ACC, 2017). Moreover, climate change and weather extremes can affect all weather-sensitive sectors.

At present, weather systems are chaotic and unseasonable (Calabretto, 2017). However, reliable weather forecasts and consideration of weather and climate risks in business, financial, and investment decisions can lower costs and drive additional revenues. Using forecast information to improve socioeconomic consequences, wealth, and investment requires: 1) identifying the most severely impacted economic sectors; 2) determining the benefits from using weather forecasts in decision making; and 3) developing models for business and investment decision-making that incorporate weather and climate forecast information (Mjelde, Sonka, \& Peel, 1989).

The National Centre for Atmospheric Research (NCAR, 2005) found that the energy, transportation, construction, agriculture, health, insurance, and other economic sectors are sensitive to weather changes. Furthermore, the investment industry has recognized that weather and climate change have impacts on investment returns. All these economic sectors can be affected differently by good and bad weather, leading to declines or increases in shareholders' investments.

Understanding the effects of weather-related factors on economically relevant outcomes-whether agricultural output, energy demand, health, insurance, construction, or transportation-is increasingly important to assess the potential economic and financial implications of weather and climate change risks. Weather-sensitive companies usually approach environmental risk in two ways. First, they consider the risk that catastrophic weather events could adversely impact revenue streams. Second, they assess the risk associated with variations in revenue arising from weather events that are not catastrophic but deviate from the norm. Significant deviations from the norm are weather extremes that reflect climate change. Thus, weather and climate risks consist of uncertainty in cash flows and earnings caused by catastrophic events and weather extremes, such as significant changes in temperature, humidity, rainfall, wind, snow, and other weather-related characteristics.

Information on weather, climate, and other environmental aspects has become a key factor in business planning, pricing, and risk management decisions. Better-informed decisions reduce risks and increase opportunities. Environmental risks also need to be included in mainstream investment decision-making to obtain a balanced view of the entire risk. This research focuses on weather and climate risks and explores the financial and market risks for weather-sensitive sectors in the context of Australia. In Australia, weather-sensitive sectors are the key players in the economy. Moreover, Australia faces significant environmental and economic impacts from climate change across weather sensitive sectors. A key objective of this research is to raise awareness of environmental issues in investment decisions and allocation of capital. Another objective is to stress the importance of weather and climate change information in investment decisions for weather-sensitive sectors and companies. To achieve these objectives, new financial model including environmental information has been developed: the MarketClimate Change Model (MCCM), which extends the market model by adding weather variables and weather-change forecast information. 
In a financial analysis, historical and forecasting data were applied to a market model and empirically examined to determine how much risk might be associated with weather variability. The moving average (MA), exponential moving average (EMA), and auto-regressive integrated moving average (ARIMA) techniques were used to test the MCCM. The EMA and ARIMA forecast modeling techniques were also employed to forecast weather patterns and predict future returns on investments. The new MCCM using environmental data has great value for weather-sensitive sectors and companies and allows market participants to consider these specific, unique risks.

\section{LITERATURE REVIEW}

It is well known that weather conditions influence the Earth and human and economic activities. Thousands of peer-reviewed academic papers are published about weather extremes and climate change every year. Most of these papers are related to environmental science (25\% of papers), earth and planetary science $(22 \%)$, and agricultural and biological sciences $(16 \%)$, with smaller amounts of research related to energy (5\%), medicine (3\%), economics, econometrics, and finance ( $2 \%$ each) (Scopus, 2015).

Weather-related information has played an important role in the economy and can significantly impact business and capital market activities. Most studies in areas of economics and finance have found substantially increased economic losses linked to an increased severity of weather extremes (Hsiang \& Narita, 2012; Loebach, 2016; Bollinger \& Mewes 2012; and others). A large percentage of the empirical literature has also analyzed the potential impact of climate change/weather extremes and focused on the significant risk implications for many areas of the economy (Ganzi \& Tanner, 1997; Lash \& Wellington, 2007; and others). Furthermore, numerous industries - such as energy, aviation, transportation, construction, insurance, and agriculture-have been shown to be significantly affected by climate and weather conditions (Ingirige, Wedawatta, \& Amaratunga, 2010; Lashley \& Warner, 2015; Phelan, 2011; Surminski \& Oramas-Dorta, 2014; Treby, Clark \& Priest, 2006; Trienekens, 2011; and others).

For example, a large segment of the empirical literature has investigated the relationship between weather-related information and variables such as electricity and gas demand (Valor, Meneu \& Caselles, 2001; and others), energy and natural gas consumption, and gas and oil prices (Boudoukh, Richardson, Shen, \& Whitelaw, 2005) in weather-sensitive markets. A number of researchers have also analyzed the relationship between energy and weather in different countries and found that demand shows a significant trend related to the seasonal effects of weather conditions and other factors related to temperature and climatic characteristics (Al-Zayer \& Al-Ibrahim, 1995; Pardo, Meneu, \& Valor, 2002; and others). This relationship has received renewed attention in light of potential climate change reseach (Auffhanner \& Aroonruengsawat, 2011; Auffhammer \& Mansur, 2012; Eskeland \& Mideksa, 2010; and others).

Researchers have also paid special attention to examining the effects of changes in weather on other weather-sensitive sectors, such as agriculture (Burke \& Emerick, 2013; Schenker \& Lobell, 2010; and others). Previous debates on the impact of climate change on agriculture have been examined and have indicated a relationship between climate and agricultural output and/or productivity (Deschenes \& Greenstone, 2007; Schlenker \& Roberts, 2009; and others).

Like other weather-sensitive sectors, aviation is also heavily affected by weather conditions. Snowstorms, thunderstorms, wind, fog, extreme temperatures, and low pressure can all significantly affect flights and their safety. Weather is the most prominent cause of flight delays and diversions. Aviation is sensitive to the weather, and no decisions can be made without considering weather conditions (Janic, 2000; and others).

The previous literature has also identified a number of potential channels through which extreme temperatures, wind, rain, cold winters, and hot summers can have negative health effects (Basu \& Samet, 2010; Currie \& Rossin-Slater, 2013; and others). The authors point out that, even in developed countries such as the United States, heat-related deaths are more pronounced in industries such as agriculture and construction (Gubernot, Anderson, \& Hunting, 2015).

An increase in extreme weather events places significant pressure on the insurance industry. Previous research has investigated the relationship between weather and insurance claims (World Bank, 2010). 
Also, as disaster risk modeling is core to the general insurance business model, the insurance industry appears to be most active on climate/weather-extreme risk-primarily on "physical" risk or "adaptation" risk (Petkov, 2014; Harwood, Paddam, Pitman and Egan, 2014).

The importance of capital markets and market reactions to environmental threats and climate change information has become a focal point for many researchers. Authors have shown that environmental issues should be a central part of investment analysis (Dowell, Hart \& Yeung, 2000 and others). Moreover, significant evidence has demonstrated that investors show interest in environmental information (Chenall \& Luchau, 1977; Epstein \& Freedman, 1994), and environmental information may lead capital markets to revise their expectations regarding investments.

Recently, an increasing number of researchers have raised important questions in the areas of environmental finance and sustainability in an Australian context (Artiach, Lee, Nelson, \& Walker, 2018; Linnenluecke, Chen, Ling, Smith, \& Zhu, 2017; Vlady 2012, and others). Moreover, Linnenluecke, Smith \& McKnight (2015) summarize the state of this newly-formed interdisciplinary field and bring together research in finance and the natural sciences to develop financial and market solutions to environmental changes. These solutions offer many opportunities for wealth and growth for sectors of the economy such as railways, electricity, information technology, biotechnology, telecommunication, and others.

In addition, long-term empirical studies have investigated how weather and climate change information could affect the market value of the weather-sensitive Australian oil and gas industry (Vlady, Roca, \& Tularam, 2008). Moreover, some studies investigated the value relevance of climate change for the Australian oil and gas industry from Efficient Market Hypothesis and behavioral finance perspectives. These studies constructed the Fama and French Model, which brought together market value (MV), bookto-market ratio $(\mathrm{B} / \mathrm{M})$, price/earnings $(\mathrm{P} / \mathrm{E})$, momentum effect, size of the firm, and extended by environmental factors (Vlady, 2012; and others).

However, there remains a need to develop a new financial model for a broad audience, and that is easy to apply. A model created in conjunction with specific techniques could be used as a forecasting model. This model could also include systematic and specific risks, allowing market participants to consider market risks and specific risks of weather and climate change in their investment decisionmaking processes.

Thus, due to significant exposure to weather and climate related risk that has risen dramatically, especially for weather-sensitive companies, and there is a need to develop a new financial model that incorporates environmental risks, and the current research intends to fill this gap.

\section{DATA AND MODELS}

\section{Country, Location and Industries Selection}

Australia's seasons are at opposite times to countries located in the northern hemisphere. While December to February is summer and March to May is autumn, when June to August is winter and September to November is spring. Australia is a continent, separated from polar regions by the Southern Ocean, and for this reason it is not subject to the movements of frigid polar air during winter. Consequently, an Australia's winter is relatively mild, so that there is no any great contrast between summer and winter temperatures (ABM, 2018).

The state of New South Wales has the largest state economy in Australia. The capital city of New South Wales, Sydney, contributes around 31\% of Australia's GDP. Sydney is Australia's finance and business center. The most weather sensitive sectors of the economy in Australia are agriculture, the energy sector, insurance, tourism, health, construction, and transport. Thus, this research concentrates on weather-sensitive sectors with geographical focus on Australia, New South Wealth state, Sydney area. The weather sensitive sectors affected by local weather are represented by following large companies that located and headquartered in Sydney:

1. AGL Energy Limited, an integrated energy company.

2. Infigen Energy develops, owns, and operates renewable energy generation assets.

3. GrainCorp Limited operates as a food ingredients and agribusiness company. 
4. Qube Holdings Limited, provides logistics services as road and rail transport

5. Qantas Airways is a largest Australian airline.

6. Sydney Airport Corporation Limited

7. CIMIC Group Limited constructs roads, rails, tunnels, airports, buildings, and others

8. Primary Health Care Limited provides services and facilities to health care providers.

9. Australian Pharmaceutical Industries Limited

10. Insurance Australia Group Limited underwrites general insurance products.

Also, this study uses the All Ordinaries Index as a proxy for the Australian capital market. The All Ordinaries Index, considered the primary indicator for the Australian equities market, contains the 500 largest securities listed on the ASX.

\section{Variables, Data and Sample Size}

The weather consists the short-term variations in the atmosphere and usually thought of in terms of temperature, wind speed, rain, pressure, humidity, and other meteorological phenomena. Extreme weather is defined as weather phenomenon indicative of an unstable climate and the extremes of historical patterns, especially severe and unseasonal weather (English Dictionary, 2018). The degree to which adverse weather conditions affect a sensitive industry can be expressed as the industry's "weather sensitivity" (Gibbs, 2000).

Weather-related variables as important factors for weather-sensitive companies, and they also have been used in previous in scientific and weather-sensitive market research (see Gabbi and Znotti, 2005; McMichel et al., 2002; and others). Following previous research, the weather-related variables such as temperature, wind speed, and rain were used in the present study (Webb, 2006; Kirono et al. 2007; Dowling \& Lucey, 2005, and others).

The Australian Bureau of Meteorology provides weather-related data. The Australian government's Sydney-based meteorological station (Station \#N066062), located in Australia's financial capital market, was used for data collection and empirical analysis in this study. All missing data were replaced with data provided by the Sydney airport meteorological station (\#N66037).

The capital market data examined in this study are the monthly share prices traded on the ASX. A total of 1000 monthly share prices for weather-sensitive companies were collected to form an equally weight portfolio. Equal weight is a type of weighting that gives the same weight and importance, to each stock in a portfolio. The present study tracks weather-related data and changes in share prices for weather-sensitive portfolio and All Ordinary Index from January 2010 to June 2018 (108 months).

\section{Models}

Market Model

According to the Market Model, "the return on a security depends on the return on the market portfolio and the extent of the security's responsiveness as measured by beta" (Farlex Financial Dictionary, 2017). The return also depends on conditions that are unique to the firm. A security's total risk can be divided into unsystematic risk, the portion peculiar to the company that can be diversified away, and systematic risk, the non-diversifiable portion that is related to changes in the stock market and is therefore unavoidable. The Market Model assumes that some security market indices, such as the S\&P 500 , represent the market portfolio.

The Market Model is a single variable regression model in which the 'alpha' return is the constant and the 'beta' is return from the security explained by the market index's return.

The Market Model allows a security's expected return to be priced using linear regression

$R_{i}=\alpha_{i}+\beta_{i}(R M)+\varepsilon_{i}$

where: $R_{i}$ is the return of portfolio $\mathrm{i}$,

$\alpha_{i}$ is a constant,

$\beta i$ is the beta or the return from the security explained by the market index's return, 
$R M$ is the market index's return, and

$\varepsilon_{i}$ is an error term for past returns not explained by the regression equation.

Beta can also refer to a measure of an asset's systematic risk relative to the index.

\section{Market-Climate Change Model}

In the new, extended Market-Climate Change Model, a security market index, such as the All Ordinary Index, represents the systematic risks, while meteorological variables such as temperature, wind, and rain represent the specific risks. To examine and predict the returns on securities of weather-sensitive sectors, the following empirical models have been developed:

Returns $=\mathrm{F}$ (market returns, temperature, wind speed, rain).

$R_{i, t}=\alpha_{i, t}+\beta_{i, 1}(R M)+\beta_{i, 2}(T)+\beta_{i, 3}(W)+\beta_{i, 4}(R)+\varepsilon_{i, t}$

where: $R_{i, t}$ are the $i$ returns of the portfolio of weather sensitive companies at time $t$;

$\alpha$ is a constant,

RM is market returns (All Ordinaries),

$\mathrm{T}$ is temperature,

$\mathrm{W}$ is wind speed,

$\mathrm{R}$ is rain, and

$\varepsilon$ is an error term

\section{METHODOLOGY}

The model was estimated using time series techniques and historical as well forecasting data. Techniques used included the Moving Average (MA), the Exponential Moving Average (EMA), and the Auto-Regressive Integrated Moving Average (ARIMA). The data could also be adjusted for seasonal patterns.

\section{Moving Average}

The moving average is sometimes also called a rolling average or a running average. The moving average is one of the most widely used statistical techniques for the technical analysis of financial or meteorological data, such as stock returns or weather data. This technique can smooth out short-term fluctuations in a series of data so that longer-term trends or cycles can be identified.

Moving averages perform the following three functions:

1. Smoothing the data; in other words, matching the data to a line,

2. Reducing the effect of temporary variations and random noise, and

3. Highlighting outliers above or below the trend.

A simple moving average is a series of numbers; each number represents the average of an interval of a specified number of previous periods. The larger the interval, the more the average smooths the data.

\section{Exponential Moving Average Techniques}

Moving averages are one of the oldest and most commonly used technical indicators. They smooth out fluctuations and trend lines to approximate a straight line. Moving averages are also one of a family of tools for time series analysis. Also, the EMA is very popular in forex trading, so much so that it is often the basis of trading strategies.

Moreover, EMA applies weighted factors to previous periods that decrease exponentially. Exponential smoothing takes all previous periods into account rather than only a designated number of previous periods. Furthermore, the EMA gives the greatest weight to recent data and an exponentially smaller weight to older data. EMA was used to analyze and forecast time series data in this study. 


\section{Auto-Regressive Integrated Moving Average (ARIMA)}

ARIMA models bring together two basic concepts in extrapolation: autoregression and moving averages. In the ARIMA, AR stands for "Autoregressive", MA for "Moving Average" and I for "Integration". In time series analysis, an ARIMA model is applied to time series data either to better understand the data or to predict future points in the series (forecasting). The ARIMA model incorporates both non-seasonal and seasonal factors in a multiplicative model:

$\operatorname{ARIMA}(p, d, q) \times(P, D, Q) S$

where $p=$ non-seasonal AR order,

$d=$ non-seasonal differencing,

$q=$ non-seasonal MA order,

$P=$ seasonal AR order,

$D=$ seasonal differencing,

$Q=$ seasonal MA order, and

$S=$ time span of repeating seasonal pattern.

\section{DESCRIPTIVE STATISTICS}

As previously mentioned, this research concentrates on weather-sensitive sectors of the Australian economy with a geographical focus on the Sydney area and uses a portfolio of weather-sensitive companies. This study tracks weather-related data and changes in the share prices of the weather-sensitive portfolio and the All Ordinary Index from January 2010 to May 2018. A series of the share prices of weather-sensitive companies and the All Ordinaries Index were converted to returns using the discrete return formula $R_{t=100} \ln \left(P_{t} P_{t-1}\right)$, where $P_{t}$ is the company or index level at the end of month $t$.

Table 1 presents the descriptive statistics of returns and weather-related monthly variables. The kurtosis of all variables does not exceed the critical value of 3 for the normal leptokurtic distribution, and skewness does not reach +1.00 , except for rain, which has a slightly higher value. The data are from the normal distribution. However, graphs 3 and 4 illustrate volatility and fluctuations over time in returns of portfolio and All Ordinaries Index.

TABLE 1

DESCRIPTIVE STATISTICS

\begin{tabular}{|l|c|c|c|c|c|}
\hline & $\begin{array}{c}\text { Portfolio } \\
\text { Return }\end{array}$ & $\begin{array}{c}\text { All Ord } \\
\text { Returns }\end{array}$ & High Temp & Wind & Rain \\
\hline Mean & 0.0047 & 0.0034 & 23.4200 & 73.1000 & 101.92 \\
\hline Median & 0.0053 & 0.0014 & 24.0000 & 73.0000 & 75.00 \\
\hline Standard Dev. & 0.0461 & 0.0334 & 3.3999 & 10.4799 & 80.86 \\
\hline Kurtosis & -0.5453 & -0.2317 & -1.0512 & -0.1652 & 1.1219 \\
\hline Skewness & -0.0295 & -0.3604 & -0.3707 & 0.2388 & 1.2487 \\
\hline Minimum & -0.0987 & -0.0809 & 17.0000 & 52.0000 & 2.00 \\
\hline Maximum & 0.0992 & 0.0713 & 30.0000 & 96.0000 & 367.00 \\
\hline
\end{tabular}

This study uses a mean high temperature for the statistical analyses. Sydney has a humid, subtropical climate, which means it has cool, mild winters and hot summers. Rain and sunshine are evenly spread throughout the year. In Sydney, the mean high temperature for the period of this study was around 23 to $24{ }^{\circ} \mathrm{C}$, with a minimum of $17^{\circ} \mathrm{C}$ and a maximum of $30^{\circ} \mathrm{C}$. 
However, in 2018 , the high temperature was $47.3{ }^{\circ} \mathrm{C}$, the highest temperature recorded by a weather station in the Sydney metropolitan area in 79 years (ABM, 2018). In May 2017, the low was $-0.9{ }^{\circ} \mathrm{C}$, the coldest temperature recorded in Sydney for 18 years. This low was accompanied by frost and fog (ABM, 2017).

The standard deviation for wind speed is 10.5 ; for rain it is 80.86 , which indicates extreme weather events such as thunderstorms and heavy rains. Winds of up to 100 kilometers per hour were recorded in this study, and rain fluctuated from 2.0 to $367 \mathrm{~mm}$, indicating droughts and floods.

Figures 1-3 show the seasonal patterns and annual cycles in weather-related variables; for this study, seasonal variations need to be removed to de-seasonalize data set.

FIGURE 1

WEATHER VARIABLE: TEMPERATURE

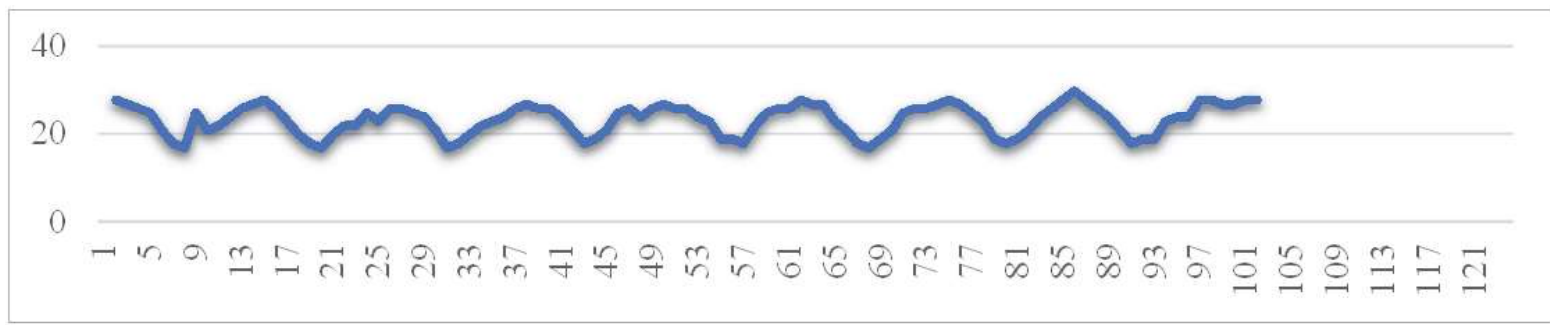

FIGURE 2

WEATHER VARIABLE: WIND SPEED

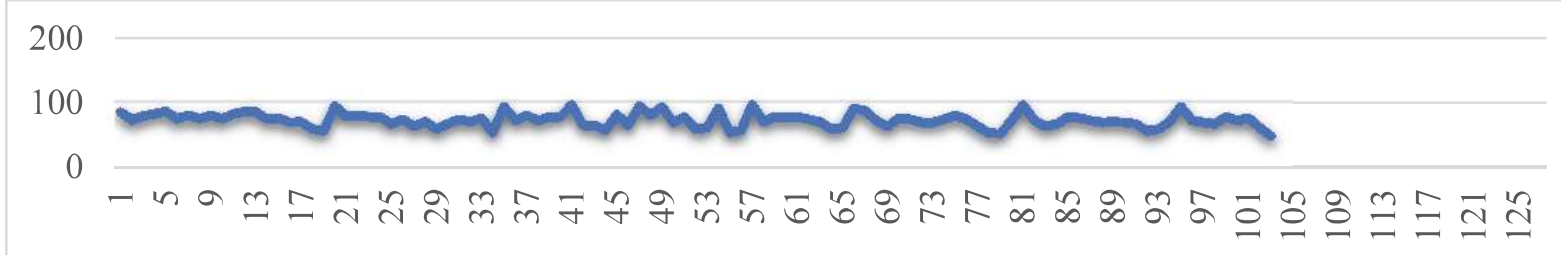

FIGURE 3

WEATHER VARIABLE: RAIN

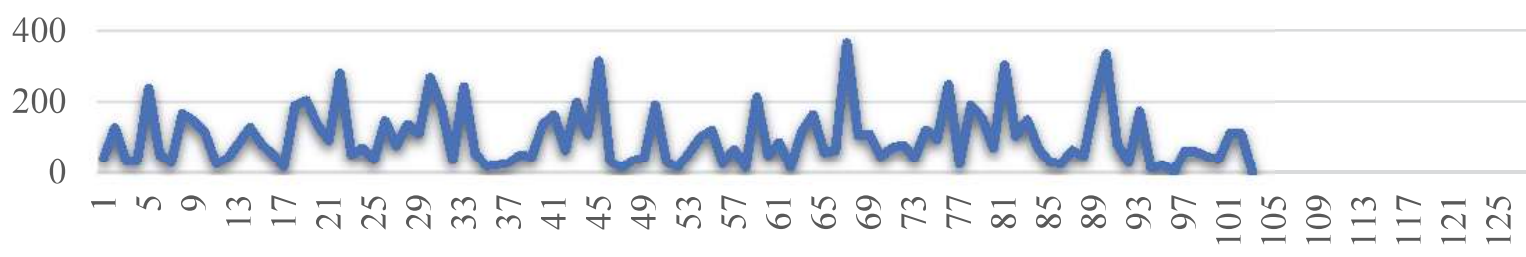

Descriptive statistics and graphs indicate that these weather-related factors vary significantly over time and across seasons.

Moving average techniques such as Exponential Weighted Moving Average, will be used to smooth out this fluctuation. Also, de-seasonalizing data process should remove the effects of seasonality and trends to show only the absolute changes in values. 


\section{GRAPHICAL ANALYSIS}

Market risk, weather risk, and time-varying rolling beta

A stock's volatility and systematic risk can be determined by calculating the beta. Beta is the key factor used in the Capital Asset Price Model (CAPM), the Security Market Line (SML), and the Market Model, three models for predicting stock returns.

Figure 4 shows 12 months of rolling betas for the weather-sensitive portfolio used in this study and for the capital market if the capital market beta is 1 . A rolling beta is a series of numbers, each of which is the average of an interval of the 12 previous months. Thus, this graph displays betas starting in 2011 .

\section{FIGURE 4 \\ 12-MONTH ROLLING BETA: PORTFOLIO OF WEATHER-SENSITIVE COMPANIES VS. THE MARKET}

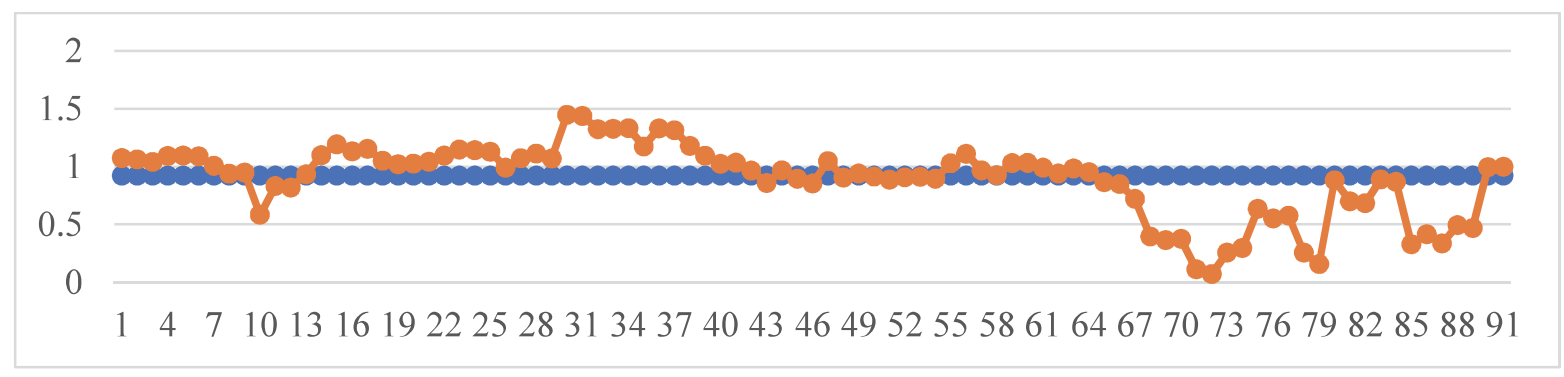

The-12 month rolling beta shows the different risk behavior of weather-sensitive stocks over a sevenyear term investment horizon. A positive beta value indicates that stocks generally move in the same direction as the market; a negative value indicates that they move in the opposite direction. The average of R-squared is 0.46 ; this measures the percentage of a security's historical price movements that can be explained by movements in a benchmark index. The average beta for the weather-sensitive portfolio is 0.89 .

In general, during period from year 2010 to middle of year 2014, the portfolio beta was more volatile, and portfolio outperformed the market. During this period, once in year 2011, the beta suddenly dropped to 0.6 and underperformed the benchmark and significantly increased to 1.5 and outperformed market in year 2013. Starting in the middle of year 2014, volatility decreased to 1.0 and then portfolio moved with the market to the middle of year 2016. In the end of year 2016, the beta decreased to 0; it then fluctuated between 0 and 1.0 during 2017 and 2018 years and mostly underperform market.

The beta highlights financial elasticity and can measure the sensitivity of portfolio's returns to market returns and its systematic or market risk. However, the returns of this portfolio also depend on conditions that are unique to the weather-sensitive companies; these returns are also exposed to weather risks.

Figures 5, 6, and 7 show the 12-month rolling betas for the weather variables temperature, wind speed, and rain. 
FIGURE 5

ROLLING BETA OF TEMPERATURE

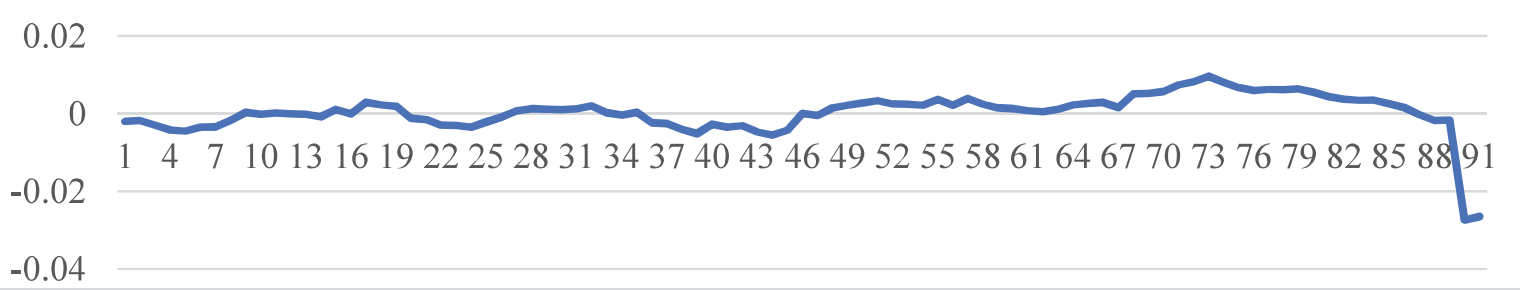

\section{FIGURE 6 \\ ROLLING BETA OF WIND SPEED}

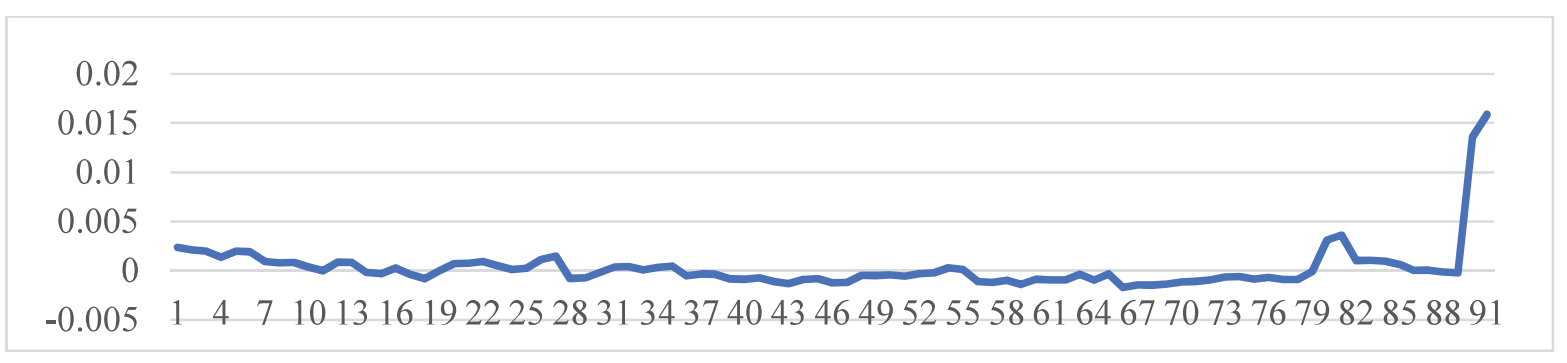

FIGURE 7

ROLLING BETA OF RAIN

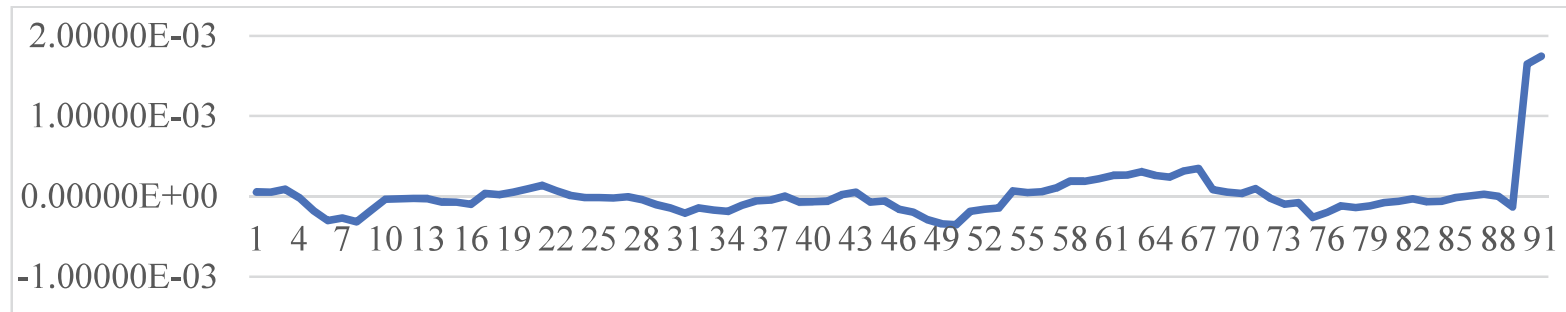

These figures indicate that weather risks increased significantly during the last three years of this study, 2016, 2017, and 2018. In 2016-2017, weather risks from temperature changes increased significantly and predicted to move in opposite direction of portfolio. Also, during the last three years, the weather risks in Sydney increased due to damaging winds, hailstones, and thunderstorms. Moreover, storms often occurred after the hottest days (ABM, 2017). The risk of drought was high in 2015-2016, but the rainfall is expected to increase in 2018.

\section{EMPIRICAL ANALYSIS}

In this section, EMA and ARIMA techniques are used to investigate the effect of weather and climate on the returns of the weather-sensitive companies examined in this study.

Returns $=$ F (market returns, temperature, wind speed, rain).

$$
R_{i, t}=\alpha_{i, t}+\beta_{i, 1}\left(R M^{\prime}\right)+\beta_{i, 2}\left(T^{\prime}\right)+\beta_{i, 3}\left(W^{\prime}\right)+\beta_{i, 4}\left(R^{\prime}\right)+\varepsilon_{i, t}
$$

where $\quad R_{i, t}$ are the i stock returns at time $t ; i=$ the portfolio of weather-sensitive companies;

$\alpha$ is a constant;

168 Journal of Strategic Innovation and Sustainability Vol. 14(2) 2019 
$R M^{\prime}$ is the smoothed market return (All Ordinaries);

$T^{\prime}$ is the smoothed and de-seasonalized average temperature;

$W^{\prime}$ is the smoothed and de-seasonalized wind speed;

$R^{\prime \prime}$ is the smoothed and de-seasonalized rain; and $\varepsilon$ is an error term.

For weather-related variables, seasonal fluctuations are generally the largest single source of fluctuation that has been neutralized using a smoothing technique. Therefore, averaging and smoothing combined with seasonal adjustments were used in this study, enabling the preparation of a regression analysis. The EMA and ARIMA programs perform seasonal adjustments and offer two options: an additive model or a multiplicative model.

\section{Exponential Moving Average with Seasonal Adjustment}

Figures 8-12 show the smoothed, seasonally adjusted financial and weather-related variables. Since seasonality have been smoothed out of these data, the figures show only the absolute changes in values. Moreover, the next year's returns can be forecasted using the annually adjusted moving average and the seasonal adjustment and multiplying by the number of periods into the future that should be predicted.

\section{FIGURE 8}

\section{SEASONALLY ADJUSTED PORTFOLIO RETURN AND 12-MONTH FORECAST}

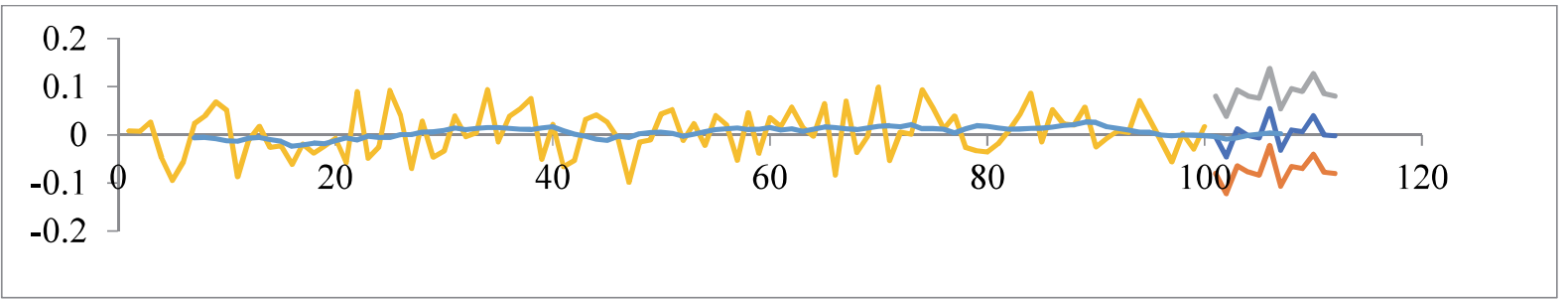

FIGURE 9

SEASONALLY ADJUSTED MARKET RETURN AND 12-MONTH FORECAST

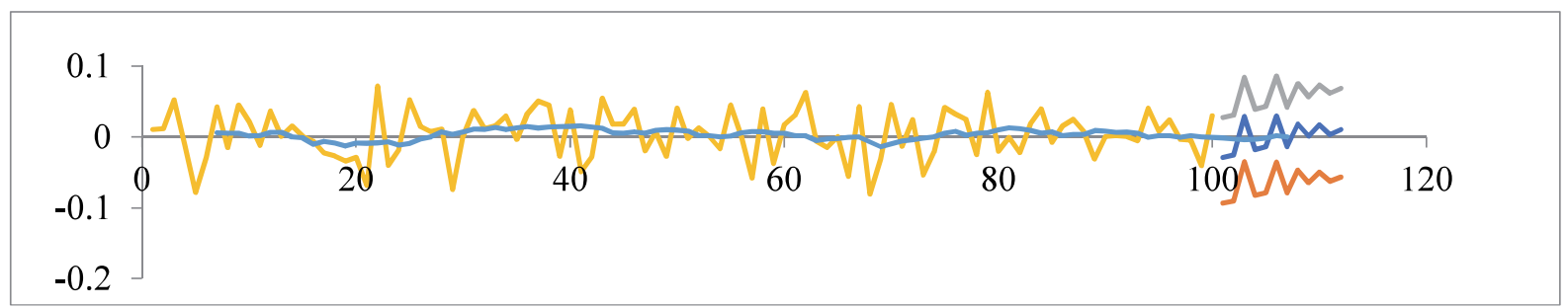

FIGURE 10

SEASONALLY ADJUSTED TEMPERATURE AND 12-MONTH FORECAST

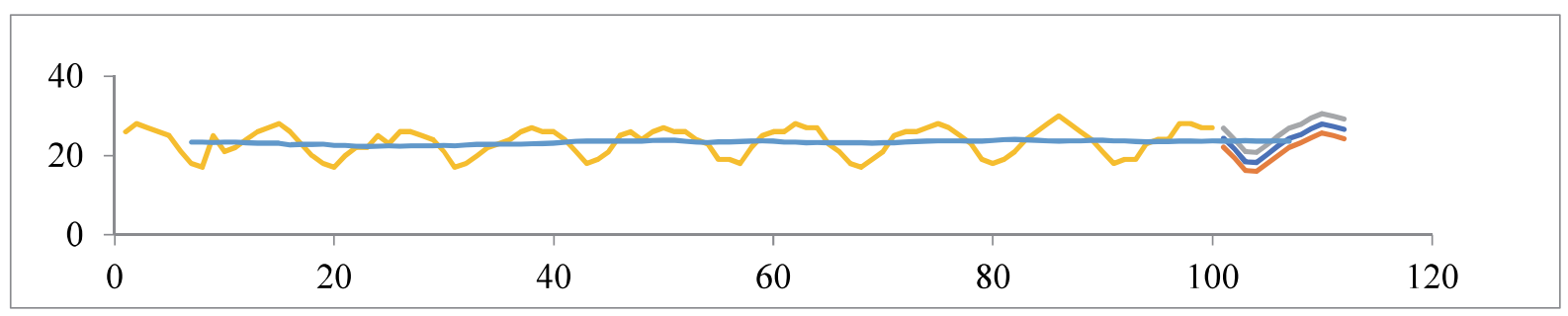


FIGURE 11

SEASONALLY ADJUSTED WIND SPEED AND 12-MONTH FORECAST

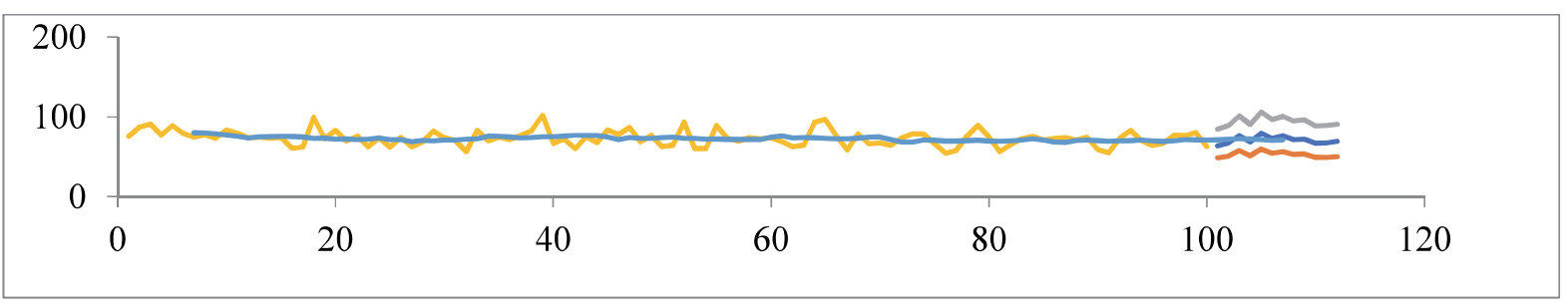

FIGURE 12

SEASONALLY ADJUSTED RAIN AND 12-MONTH FORECAST

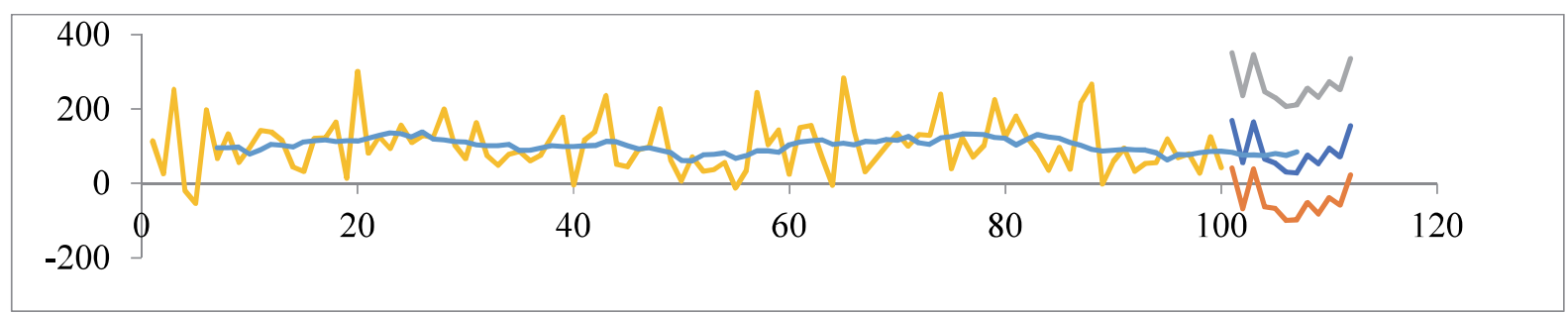

\section{EMPIRICAL RESULTS}

Table 2 shows the results of the Market-Climate Change Model for EMA and ARIMA historical and forecasting models, where all variables were adjusted using the 12-month EMA in combination with multiplicative seasonal adjustment.

TABLE 2

MARKET - CLIMATE CHANGE MODEL

$$
R_{i, t}=\alpha_{i, t}+\beta_{i, 1}\left(R M^{\prime}\right)+\beta_{i, 2}\left(T^{\prime}\right)+\beta_{i, 3}\left(W^{\prime}\right)+\beta_{i, 4}\left(R^{\prime}\right)+\varepsilon_{i, t}
$$

\begin{tabular}{|c|c|c|c|c|c|c|c|}
\hline Models & $\mathrm{R}^{2}$ & $\mathrm{~F}$ & Intercept & $\begin{array}{l}\text { Market } \\
\text { Return' }\end{array}$ & Temperature' & Wind Speed' $^{\prime}$ & Rain' \\
\hline EMA & .4047 & 15.57 & \begin{tabular}{|l|}
.0146 \\
$(.0617)$ \\
\end{tabular} & \begin{tabular}{|l}
$.6553 * * *$ \\
$(.1455)$ \\
\end{tabular} & $\begin{array}{l}.0054^{* *} \\
(.0022) \\
\end{array}$ & $\begin{array}{l}-.0017 * * * \\
(.0003)\end{array}$ & $\begin{array}{l}.0001 * * * \\
(4.7 \mathrm{E}-05) \\
\end{array}$ \\
\hline $\begin{array}{l}\text { EMA } \\
\text { 24-Forecast }\end{array}$ & .4242 & 19.71 & \begin{tabular}{|l|}
.0210 \\
$(.0570)$ \\
\end{tabular} & $\begin{array}{l}.6904 * * * \\
(.1209) \\
\end{array}$ & $\begin{array}{l}.0041^{* *} \\
(.0021) \\
\end{array}$ & $\begin{array}{l}-.0015^{* * *} \\
(.0002) \\
\end{array}$ & $\begin{array}{l}.0002 * * * \\
(3.59 \mathrm{E}-05)\end{array}$ \\
\hline $\begin{array}{l}\text { 12-ARIMA } \\
(1,1,1),(0,1,1)\end{array}$ & .4949 & 22.05 & \begin{tabular}{|l|}
$-.0211^{* * * *}$ \\
$(.0035)$ \\
\end{tabular} & \begin{tabular}{|l}
$.05873 * * *$ \\
$(.1278)$ \\
\end{tabular} & $\begin{array}{l}.0048 * * * \\
(.0010) \\
\end{array}$ & \begin{tabular}{|l}
$-.0013 * * *$ \\
$(.0003)$ \\
\end{tabular} & $\begin{array}{l}9.9 \mathrm{E}-05^{* *} \\
(4.7 \mathrm{E}-05)\end{array}$ \\
\hline $\begin{array}{l}\text { 12-ARIMA } \\
(1,1,1),(0,1,1) \\
24 \text {-Forecast }\end{array}$ & .3909 & 17.48 & $\begin{array}{l}-.0046^{* *} \\
(.0018)\end{array}$ & $\begin{array}{l}.5948^{* * * *} \\
(.1249)\end{array}$ & $\begin{array}{l}.0036^{* * *} \\
(.0098)\end{array}$ & $\begin{array}{l}-.0012 * * * \\
(0.00031)\end{array}$ & $\begin{array}{l}9.88 \mathrm{E}-05 * * * \\
(4.2 \mathrm{E}-05)\end{array}$ \\
\hline
\end{tabular}

Standard Error in parentheses

Statistical significance $* * *, * *, *$ are significance at the 1,5 , and 10 percent level respectively

All weather-related variables are exponentially smoothed and seasonally adjusted

$\mathrm{F}(\mathrm{p}<0.05)$

\section{EMA Model}

EMA also known as an exponentially weighted moving average (EWMA) where to most recent periods are given greater weight. Recent data is proportionally more useful than older data. Row 1 in 
Table 2 shows that $\mathrm{R}$-square value is $40 \%(\mathrm{~F}=15.57, \mathrm{p}<0.05)$, implying a relationship between the returns of the stocks in the portfolio and their betas. The alpha value (intercept) in this model is $-0.014(\mathrm{t}$ $=-0.2371$ ). This is negative and insignificant, indicating that the portfolio is underperforming the market index.

The estimated slopes are significant for all variables. Moreover, the statistically significant and positive coefficients are the market beta, $0.6553(\mathrm{p}<0.01 ; \mathrm{t}=4.0527)$, which represents systematic risk; the temperature, $0.0054(\mathrm{p}<0.05 ; \mathrm{t}=2.4618)$; and rain $0.0001(\mathrm{p}<0.01 ; \mathrm{t}=2.9104)$. Wind speed is $0.0017(\mathrm{p}<0.01 ; \mathrm{t}=-4.8348)$; it is negative and significant and is associated with storms and other weather extremes that usually have a negative effect on share prices. This indicates that both systematic and non-systematic risks influence the portfolios' risk premiums, since these numbers are all significantly different from 0 .

Another major advantage of exponential smoothing method is that it offers good forecasts in a wide variety of applications. The real-time forecast calculated using the EMA method weighs real-time observation more heavily than historical data.

\section{EMA-24 Months Forecast}

Row 2 in Table 2 shows the historical and forecasted results of the Market-Climate Change Model, which combines exponential smoothing with seasonal adjustment. The 24-month forecast predicts that all slope coefficients will remain significant except the intercept, which represents the alpha. The alpha value could drop slightly from $-0.014(\mathrm{t}=-0.2371)$ to $-0.0021(\mathrm{t}=-0.0370)$, but it is expected to remain negative and insignificant, indicating that the portfolio will continue to underperform the market index, the All Ordinary. The R-square value could increase from 0.40 to 0.42 , and the F value could change from 15.46 to 19.71 .

The market beta $0.6553(\mathrm{p}<0.01 ; \mathrm{t}=4.0527)$ could increase to $0.6904(\mathrm{p}<0.01 ; \mathrm{t}=5.7088)$, indicating higher expected returns. The risk from temperature changes will change from $0.0054(\mathrm{p}<0.05$; $\mathrm{t}=2.4618)$ to $0.0041(\mathrm{p}<0,05 ; \mathrm{t}=1.9958)$, indicating that temperature could affect the portfolio's returns slightly less than it currently does. Rain could affect the portfolio more significantly; the rain is expected to increase from $0.0001(\mathrm{p}<0.01 ; \mathrm{t}=2.9104)$ to $0.0002(\mathrm{p}<0.01 ; \mathrm{t}=4.7425)$. Furthermore, wind speed which is associated with dangerous weather extremes, could have a slightly smaller adverse effect on the returns of weather-sensitive companies; it is predicted to change from $-0.0017(\mathrm{p}<0.01 ; \mathrm{t}=-4.8348)$ to $0.0015(\mathrm{p}<0.01 ; \mathrm{t}=-5.5080)$.

ARIMA $(1,1,1) \times(0,1,1)-12$

To re-fit the regression model as an ARIMA model with regressors, it is necessary to specify the appropriate $\mathrm{AR}$ and/or MA terms to fit the pattern of autocorrelation observed in the original residuals.

Positive ACF values and a high number of lags suggested an order of difference equal to $1(\mathrm{~d}=1)$. The non-seasonal AR order is $1(\mathrm{p}=1)$ and is equal to the first lag where the PACF value is above the significance level. For one lag, the ACF value is above the significance level and the non-seasonal MA order is $1(\mathrm{q}=1)$. The time series data in this study have an unstable seasonal pattern over time, and for this reason, $\mathrm{D}=1$. The $\mathrm{ACF}$ is also negative at lag $\mathrm{S}$, which is 12 ; thus, $\mathrm{P}=0$ and $\mathrm{Q}=1$. Thus, the 12 month ARIMA $(1,1,1) \times(0,1,1)$ is used to confirm or reject the effect of market and weather risks on portfolio returns.

Row 3 in Table 2 shows that the R-square value is $49.49 \%(\mathrm{~F}=22.04, \mathrm{p}<0.05)$, implying a relationship between returns of the stocks in the portfolio and their betas. Market and weather risks account for $49.49 \%$ of the variation in portfolio returns. The intercept, $-0.021(\mathrm{p}<0.01 ; \mathrm{t}=-5.9945)$, is negative and insignificant, indicating that the portfolio is underperforming the market index.

The betas are significant for all variables. The statistically significant and positive coefficient is the market beta, $0.5872(\mathrm{p}<0.01 ; \mathrm{t}=4.1130)$, which represents a systematic risk. Weather risks are represented by temperature, which is $0.0048(\mathrm{p}<0,01 ; \mathrm{t}=4.7444)$, and rain, which is $0.000098(\mathrm{p}<0.05$; $\mathrm{t}=1.9871)$; these factors also significantly affect weather-sensitive companies. The wind speed, -0.0013 $(\mathrm{p}<0.01 ; \mathrm{t}=-4.0831)$, is negative and significant; it is associated with weather extremes that negatively 
affect the portfolio's returns. Thus, like the EMA model, the ARIMA model $(1,1,1) \times(0,1,1)$ confirms that systematic risks and non-systematic weather risks influence the portfolios' risk premiums.

\section{ARIMA Forecast}

Row 4 in Table 2 shows the forecasted results of the Market-Climate Change Model with seasonal adjustments and corrections for autocorrelated errors. The 24-month forecast indicates that all slope coefficients are significant, including the intercept. The R-square value could decrease from 0.4949 to 0.3909 , and the $\mathrm{F}(\mathrm{p}<0.05)$ value could change from 0.2248 to 0.1748 . The alpha value could change slightly from $-0.0211(\mathrm{p}<0.01 ; \mathrm{t}=-5.9945)$ to $-0.046(\mathrm{p}<0.05 ; \mathrm{t}=-2.5361)$, but it will remain significant, indicating that the portfolio could underperform the All Ordinary Index.

The market beta $0.5872(\mathrm{p}<0.01 ; \mathrm{t}=4.1130)$ could slightly increase to $0.5948(\mathrm{p}<0.01 ; \mathrm{t}=4.7622)$. The risks from temperature changes will go from $0.0048(\mathrm{p}<0.01 ; \mathrm{t}=4.7444)$ to $0.0036(\mathrm{p}<0.01 ; \mathrm{t}=$ 3.7124); these risks could affect the portfolio's returns to a slightly lesser degree. The effect of rain will remain essentially the same, changing from $0.985-\mathrm{E} 05(\mathrm{p}<0.05 ; \mathrm{t}=2.0871)$ to 0.988 -E05 $(\mathrm{p}<0.01 ; \mathrm{t}=$ 4.7425). Risks from wind speed will change from $-0.0013(\mathrm{p}<0.01 ; \mathrm{t}=-4.0831)$ to $-0.0012(\mathrm{p}<0.01 ; \mathrm{t}=$ -3.7496); hopefully, there will not be more dangerous weather extremes.

\section{SUMMARY AND DISCUSSION}

Table 3 summarizes the results of the statistical analysis used to test a Market-Climate Change Model that investigates the explanatory power of market risk and specific weather/climate change risk for a portfolio that includes weather-sensitive companies.

All results confirmed that market (systematic) and weather/climate change risks (non-systematic) risks influence the portfolios' risk premiums. There were no significant differences among the results of the different techniques and models used in this study.

TABLE 3

MARKET-CLIMATE CHANGE MODEL

$$
R_{i, t}=\alpha_{i, t}+\beta_{i, 1}\left(R M^{\prime}\right)+\beta_{i, 2}\left(T^{\prime \prime}\right)+\beta_{i, 3}\left(W^{\prime}\right)+\beta_{i, 4}\left(R^{\prime}\right)+\varepsilon_{i, t}
$$

\begin{tabular}{|l|l|l|l|l|}
\hline & EMA & ARIMA & EMA & ARIMA \\
\hline & Historical & \multicolumn{2}{l|}{} \\
\hline Intercept $\boldsymbol{\alpha}_{\mathrm{i},}$ & -0.0140 & $-0.0211^{* * *}$ & -0.0210 & $-0.0460^{* *}$ \\
\hline Market Returns' & $0.6553^{* * *}$ & $0.5872^{* * *}$ & $0.6904^{* * *}$ & $0.5948^{* * *}$ \\
\hline Temperature' & $0.0054^{* *}$ & $0.0048^{* * *}$ & $0.0041^{* *}$ & $0.0036^{* * *}$ \\
\hline Wind Speed' & $-0.0017^{* * *}$ & $-0.0013^{* * *}$ & $-0.0015^{* * *}$ & $-0.0012^{* * *}$ \\
\hline Rain' & $0.0001^{* * *}$ & $0.0000985^{* *}$ & $0.0002^{* * *}$ & $0.0000988^{* *}$ \\
\hline R-Square & 0.4073 & 0.4949 & 0.4242 & 0.3909 \\
\hline F, p $<\mathbf{0 . 0 5}$ & 15.46 & 22.05 & 19.71 & 17.48 \\
\hline
\end{tabular}

Statistical significance $* * *, * *, *$ are significance at the 1,5 , and 10 percent level respectively

With the ARIMA model, the alpha (intercept) was statistically significant; with the EMA model, the alpha was insignificant. However, the alpha was negative for all models, indicating that the portfolio does not perform better than the market index, but it is closed to zero. When the alpha is close to zero, the investment earns an adequate return relative to its risk.

Beta is a measure of the risk arising from general market movements as opposed to idiosyncratic factors. The market portfolios of all investable assets have a beta of exactly 1 . In this study, all the models resulted in market betas below 1 (around 0.58 to 0.69 ) for the portfolio. This can indicate either that an investment is less volatile than the market, or that the investment is volatile, but its price movements are 
not highly correlated with the market. The forecasting models in this study resulted in higher alpha and more significant beta coefficients.

As shown in Figure 4, 12-Month Rolling Beta: Portfolio of Weather-Sensitive Companies vs. the Market, the rolling beta of our portfolio fluctuated from 0.1 to 1.5. From 2010 to the middle of 2014, the beta was greater than 1; from the middle of 2014 until the middle of 2016, the beta was around 1 and moved with the market; starting in the middle of 2016, the beta was less than 1 and dropped to almost 0 ; and in 2018, the beta approached 1 again.

The summary of the results of this study indicates that all weather-related variables are significant and influence the returns of the weather-sensitive companies included in the study. The risk of temperature changes is positive and statistically significant. The risk of rain is also significant and would positively affect the returns of a weather-sensitive portfolio. However, the beta coefficient here is very small. Moreover, the descriptive statistics in Table 1 and Figure 3 indicate that rainfall fluctuates from 0 to 367, and the standard deviation of 80.85 indicates high volatility and high risk. Figure 6 also shows jumps and trends in monthly rainfall in addition to droughts and moderate amounts of rainfall. Figures 5 and 6 also show that high rainfall is associated with strong winds. Finally, the summarized results confirm that high wind speeds are statistically significant and negatively affect the returns of weather-sensitive companies.

Figures 5, 6, and 7 show the 12-month rolling betas for temperature and wind speed. These betas indicate that risks related to weather have increased significantly over the last three years (2016-2018). In 2016 and 2017, the weather-related risks from temperature changes and wind speeds increased significantly.

Finally, the forecasting models suggest that the portfolio of weather-sensitive companies will move closer to the rest of the market. Wind speed, which is associated with dangerous weather extremes, could become weaker and have a slightly less adverse effect on the returns of weather-sensitive companies. Temperature is expected to decrease, and moderate rainfall is expected to increase. Nevertheless, it is important to understand that, as the effects of climate change increase and could be unpredictable.

\section{CONCLUSION}

The frequency of unseasonable weather has increased, and the severity of weather events is increasing every year. The purpose of this study is to develop a new financial model for a broad audience that includes environmental factors and can support sound investment decisions. The Market-Climate Change Model is an extended market model that includes, along with financial data, weather-related variables such as temperature, wind speed, and rain.

In this study, MA, EMA, and ARIMA models have been used to test the explanatory power of weather-related variables and to forecast the weather and predict future returns on investments in weathersensitive companies. The EMA is easy to use; the ARIMA is a more complex model. However, there were no significant differences among the results produced by the different techniques and models used in this study. All the results indicate that weather-related variables have significant effects on the returns of weather-sensitive companies. Thus, the Market-Climate Change Model could be very useful to any weather-sensitive company or industry; it allows market participants to consider the financial risk of weather and climate change in their decision-making process. 


\section{REFERENCES}

Al-Zayer, J., \& Al-Ibrahim, A. (1996). Modelling the impact of temperature on electricity consumption in Eastern Province of Saudi Arabia. Journal of Forecasting, 15.

Artiach, T., Darren, L., Nelson, D., \& Walker, J. (2018). The determinant of corporate sustainability performance, Accounting and Finance, 50(1), 31-51.

Auffhanner, M., \& Aroonruengsawat, A. (2011). Simulating the impacts of climate change, prices and population on California's residential electricity consumption. Climatic Change, 109(S1), 191210.

Auffhammer, M., \& Mansur, E.T. (2012). Measuring climatic impacts on energy consumption: A review of the empirical literature, Energy Economics, 14, 522-530.

Australian Bureau of Meteorology (2018). Monitoring the weather. Retrieved from http://www.bom.gov.au/info/ftweather/page

Australian Climate Council (2017). Climate Report 2016-2017. Retrieved from www.climatecouncil.org.au/2017/12/07/annual-report-17/

Basu, R., \& Samet. J.M. (2010). An exposure assessment study of ambient heat exposure in an elderly population in Baltimore, Maryland. Environmental Health Perspectives, 110(12), 1219-1224.

Bollinger, K., Mewes, H., Janssen, A., \& Strasser, C. (2012). Facing the Impacts of Climate Change: Indian MSMEs and Adaptation. New Dehli: GIZ.

Boudoukh, J., Richardson, M., Shen, Y.Q., \& Whitelaw, R.F. (2005). Do asset prices reflect fundamentals? Freshly squeezed evidence from OJ market. Journal of Financial Economics, 83(2), 271-530.

Burke, M., \& Emerick, K. (2013). Adaptation to climate change: Evidence from US agriculture. American Economic Journal: Economic Policy, 8(3), 106-40.

Calabretto, S. (2017, August 15). Weather system are chaotic and unpredictable. Weather Zone, Australian News, p.1.

Chenall, H.H., \& Luchau, R. (1977). Investor information needs - An Australian study. Accounting and Business Research, 26, Spring

Currie, J., \& Rossin-Slater, M. (2013). Weathering the storm: Hurricanes and birth outcomes. Journal of Health Economics, Elsevier, 32(3), 487-503.

Deschênes, O., \& Greenstone, M. (2007). The economic impacts of climate change: evidence from agricultural output and random fluctuations in weather. American Economic Review, 97(1), 354385.

English Dictionary (2018). Princeton University. Retrieved from http://www.hyperdictionary.com/dict-e

Epstein, M.J., \& Freedman, M. (1994). Social disclosure and the individual investor. Accounting, Auditing \& Accountability Journal, 7(4), 94-109.

Eskeland, G., \& Mideksa, M. (2010). Electricity demand in a changing climate. Mitigation and Adaptation Strategies for Global Change, 15(8), 877-897.

Farlex (2017). The Farlex Financial Dictionary: Business and Investing Terms Explained. Retrieved from https://www.amazon.com/Farlex-Financial-Dictionary-Investing-Explained

Gabbi, G., \& Znotti, G. (2005, June). Climate variables and weather derivatives: Gas demand, temperature and seasonality effects in the Italian case. University Boccony, Italy.

Ganzi, J.T., \& Tanner, J. (1997). Global survey on environmental policies and practices of the financial service industry: The private sector. Washington, DC: National Wildlife Federation.

Gibbs, M. (2000). Data debate heats up. Risk Waters Group Ltd. Retrieved from www.financewise.com/public/edit/energy/weahter

Greenberg, J. (1976). Economic benefits of improved meteorological forecasts. In weather forecasting and weather forecasts: Models systems and users. Colo. National Center for Atmospheric Research, 2, 608-629.

Hydrometeorological Centre of Russia (2018). Weather Conditions. Retrieved from https://www.natureindex.com 
Ingirige, B., Wedawatta, G., \& Amaratunga, D. (2010). Building up resilience of construction sector SMEs and their supply chains to extreme weather events. International Journal of Strategic Property Management, 4, 362-375.

Harwood, J., Paddam, S., Pitman, A., \& Egan, J. (2014, November). Can actuaries really afford to ignore climate change? Presented to the Actuaries Institute General Insurance Seminar, 17 - 18. Sydney, Australia.

Hsiang, S.M., \& Narita, D. (2012). Adaptation to cyclone risk: Evidence from the global cross-section. Climate Change Economics, 3(2).

Janic, M. (2000). An assessment of risk and safety in civil aviation. Journal of Air Transport Management, $6(3,50$.

Lash, J., \& Wellington, F. (2007, March 1). Competitive advantage on a warming planet. Harvard Business Review.

Lashley, J. G., \& Warner, K. (2015). Evidence of Demand for Microinsurance for Coping and Adaptation to Weather Extremes in the Caribbean. Climatic Change, 133(1), 101-112.

Linnenluecke, M. K., Chen, X., Ling, X., Smith, T., \& Zhu, Y. (2017). Research in finance: A review of influential publications and a research agenda. Pacific-Basin finance journal, 43, 188-199.

Linnenluecke, M. K., Smith, T., \& McKnight, B. (2016). Environmental finance: a research agenda for interdisciplinary finance research, Economic Modelling, 59, 124-130.

Loebach, P. (2016). Household migration as a livelihood adaptation in response to a natural disaster: Nicaragua and Hurricane Mitch. Population and Environment, 1-22.

McMichael, A.R., et al. (2002). Human health and climate change in Oceania: A risk assessment. Commonwealth of Australia, Canberra, ACT.

Mjelde, J.W., Sonka, S.T., \& Peel, D.S. (1989). The Socioeconomic Value of Climate and Weather Forecasting: Review (Research Report No. 89-01). Midwestern Climate Center, Climate and Meteorology Section, Illinois State Water Survey, Champagne, IL.

Munich Re. (2017, February). Geo risks research. Nat Cat SERVICE, Insurance Information Institute.

National Oceanic and Atmospheric Organization (2016). Climate.gov, Siberian Times.

The National Center for Atmospheric research (2005). Weather sensitive sectors. Retrieved from https://ncar.ucar.edu/where-we-focus/weather

Pardo, A., Meneu, V., \& Valo R.E. (2002). Temperature and seasonality influences on Spanish electricity load. Energy Economics, 24, 55-70.

Petkov, M. (2014, September 3). Climate change could sting reinsurers that underestimate its impact, Standard \& Poor. Retrieved from https://www.globalcreditportal.com/ratingsdirect/renderArticle.

Phelan, L. (2011). Managing Climate Risk: Extreme Weather Events and the Future of Insurance in a Climate-Changed World. Australasian Journal of Environmental Management, 18(4), 223-232.

Rice, D. (2018, January). Do you think you're cold? How does 88 below zero sound? USA Today, p.1.

Schlenker, W., \& Lobell, D.B. (2010) Robust negative impacts of climate change on African agriculture. Environ Res Lett, 5, 1-8, doi:10.1088/1748-9326/5/1/014010

Schlenker.W., \& Roberts, J. (2009, September 15). Non-linear temperature effects indicate severe damages to U.S. crop yields under climate change. PNAS, 106 (37).

Scopus (2015). Total number of climate change papers published, by year. Rosamund Pearce, Carbon Brief.

Surminski, S., \& Oramas-Dorta, D. (2014). Flood Insurance Schemes and Climate Adaptation in Developing Countries. International Journal of Disaster Risk Reduction, 7, 154-164.

Trienekens, J. H. (2011). Agricultural Value Chains in Developing Countries: A Framework for Analysis. International Food and Agribusiness Management Review, 14(2).

Thielemann, U. (2000). A brief theory of the market - ethically focused. International Journal of Social Economics, 27(1), 6-31.

U.S. National Weather Service [NWS]. (2018, January). Snows storms 2018. Retrieved from https://www.weather.gov/cae/Jan_03_2018_Snow_Event.html 
Valor E., Meneu V., \& Caselles V. (2001). Daily air temperature and electricity load in Spain. Journal of Applied Meteorology, 40, 1413-1421.

Vlady, S. (2012). Climate Change, Oil \& Gas Industry, and Investors. Lambert: Academic Publishing, $376 \mathrm{p}$.

Vlady, S., Roca, E., \& Tularam, G.A. (2008). The market value of Australian oil and gas industry and climate change: The VAR, ARCH and GARCH approaches. Studies in Regional \&Urban Planning (SRUP) 11b, 195-220.

Webb, L.B. (2006). The Impact of Projected Greenhouse Gas-Induced Climate Change on the Australian Wine Industry. Unpublished $\mathrm{PhD}$ Thesis, University of Melbourne, Melbourne, Australia.

Weiss, E.B. (1982). the value of seasonal climate forecasts in managing energy resources, Journal of Applied Meteorology, 21(4), 10-517.

World Bank (2010). World Development Report 2010: Development and Climate Change. Retrieved from http://go.worldbank.org/BKLQ9DSDU0 